\title{
ANÁLISE DE VARIÁVEIS LIMNOLÓGICAS DA ÁGUA DO RESERVATÓRIO ERNESTINA, RS, A PARTIR DA INFLUÊNCIA DO USO E COBERTURA DA TERRA E PRECIPITAÇÃO PLUVIOMÉTRICA
}

\author{
Janderlei Velasque Dal Osto ${ }^{(a)}$, Eduardo André Kaiser ${ }^{(b)}$, Waterloo Pereira Filho ${ }^{(\mathrm{c})}$, João Victor Nolasco \\ Palma ${ }^{(\mathrm{d})}$ \\ (a) Departamento de Geociências, Universidade Federal de Santa Maria, janderleijunior@gmail.com \\ (b) Departamento de Geociências, Universidade Federal de Santa Maria, kaiser-eduardo@ hotmail.com \\ (c) Departamento de Geociências, Universidade Federal de Santa Maria, waterloopf@ gmail.com \\ (d) Departamento de Geociências, Universidade Federal de Santa Maria, joaopalmavictor@gmail.com
}

Eixo: Uso e ocupação das terras e legislação ambiental

\begin{abstract}
Resumo
Os processos relacionados ao uso e cobertura da terra, em conjunto com as ações antrópicas são responsáveis pelas mudanças relacionadas a superfície terrestre, bem como das características da água. Deste modo o presente trabalho teve como objetivo analisar a influência da precipitação pluviométrica e do uso e cobertura da terra em variáveis limnológicas da bacia hidrográfica do reservatório Ernestina. Utilizando uma imagem do sensor OLI do satélite LANDSAT 8 realizou-se a classificação do uso e cobertura da terra. Os dados de precipitação foram adquiridos através do site do Instituto Nacional de Meteorologia. Assim, foi possível observar as influências dos mesmos nas variáveis limnológicas: Temperatura, Total de Sólidos em Suspensão e Condutividade Elétrica. A Condutividade Elétrica teve seus resultados diretamente relacionados a precipitação pluviométrica. Já o Total de Sólidos em Suspensão apresentou variações que estão relacionados com o uso e cobertura da terra nas margens, juntamente com a precipitação pluviométrica.
\end{abstract}

Palavras chave: Limnologia; Precipitação pluviométrica; Uso e cobertura da Terra.

\section{Introdução}

Acompanhando a demanda energética a fim de alimentar o desenvolvimento industrial e abastecimento populacional do país, a construção de usinas hidrelétricas e respectivos reservatórios vêm avançando no decorrer dos anos, com o objetivo de aproveitar o potencial hídrico brasileiro, bem como as variadas amplitudes físicas do relevo (ESTEVES, 1998). Porém, a favor desse crescimento hidroelétrico, o crescimento populacional traz consigo uma série de impactos no meio ambiente, em potencial no ecossistema aquático.

O despejo de material orgânico no corpo hídrico, resultado das atividades antropogênicas, como esgoto doméstico, resíduos poluidores, substâncias tóxicas, ou seja, o excesso de nutrientes que acabará 
caracterizando então o processo de eutrofização bem como a degradação da qualidade das águas (Hadlich e Scheibe, 2007).

Outra atividade humana que vem a influenciar nas características qualitativas e limnológicas da água é o uso da terra. A retirada da cobertura vegetal do solo possibilita o aumento do escoamento superficial e consequente transporte de sedimentos para o leito fluvial, por sua vez influenciando nas características físicas, químicas e ecológicas do reservatório. Segundo o manual de medições in loco proposto pelo CPRM (Serviço Geológico do Brasil), os parâmetros de qualidade da água que serão abordados: Temperatura da água e Condutividade Elétrica (CE), são obtidos através de medições in loco. Já o Total de Sólidos em Suspensão (TSS) é obtido através de análises em laboratório.

A temperatura é caracterizada pela medida da intensidade de calor expresso em uma determinada escala, sendo a escala dos graus centígrados ou graus Celsius $\left({ }^{\circ} \mathrm{C}\right)$ a mais usada, cuja variação poder ser dada de $0^{\circ} \mathrm{C}$ até $30^{\circ} \mathrm{C}$.

A condutividade elétrica se define pela capacidade de uma solução aquosa de conduzir uma corrente elétrica em consequência da presença de íons, podendo variar com a influência da temperatura. Seguindo o padrão imposto pelo Sistema Internacional de Unidades (S.I), as medidas de condutividade elétrica podem ser expressas preferencialmente em microSiemens $(\mu \mathrm{S} / \mathrm{cm})$ ou Milisiemens por centímetro $(\mathrm{mS} / \mathrm{cm})$. O transporte de materiais para dentro do reservatório causado pelo escoamento superficial acabará influenciando na condutividade elétrica que por sua vez depende da composição iônicas dos corpos d'água (Esteves, 1998).

Por sua vez, o TSS é compreendido pelos sólidos orgânicos e inorgânicos em suspensão, onde a fração orgânica é representada principalmente pelo fitoplâncton e substâncias húmicas, e a fração inorgânica é constituída principalmente por silte e argila. (TODESCHINI, 2004; ESTEVES, 1998).

A Usina Hidrelétrica de Ernestina, na ordem cronológica é a primeira dos cinco aproveitamos de Responsabilidade da Companhia Estadual de Distribuição de Energia Elétrica (CEEE), bem como, a primeira na ordem da cascata do Rio Jacuí. Esta usina entrou em operação no ano de 1957, possui uma potência instalada de $4.800 \mathrm{~kW}$ e sua localização geopolítica fica no município de Tio Hugo, na porção centro-norte do Estado do Rio Grande do Sul (COAJU, 2009).

Deste modo o presente trabalho teve como objetivo analisar a influência da precipitação pluviométrica e do uso e cobertura da terra em variáveis limnológicas da bacia hidrográfica do reservatório Ernestina no mês de janeiro de 2016 . 


\section{Metodologia}

Para se adquirir os resultados alusivos à influência do uso e cobertura da terra e da pluviometria nas variáveis limnológicas que foram observadas no reservatório Ernestina utilizou-se as seguintes atividades para realizar a coleta dos dados: Identificação das precipitações pluviométricas no período anterior ao trabalho de campo no qual foi realizada a coleta da água; Classificação do uso da terra a partir de imagens de satélite sensor OLI do satélite LANDSAT 8 e por fim a amostragem da água com coletas de dados in loco e em laboratório.

Os dados de precipitação pluviométrica relativos ao município de Passo Fundo (município mais próximo ao reservatório com dados disponíveis) foram obtidos no site do Instituto Nacional de Meteorologia (INMET) referentes aos 30 dias anteriores ao trabalho de campo que foi realizado no dia 25 de janeiro de 2016.

O trabalho de campo foi realizado no dia 25 de janeiro de 2016 para realizar as coletas de água referentes a seis estações amostrais que estão localizadas no reservatório Ernestina. Utilizou-se a distribuição equidistante entre as estações como critério para suas localizações. Em cada uma destas estações foram coletadas amostras de água para a determinação de algumas variáveis limnológicas em laboratório, como a condutividade elétrica (CE), o total de sólidos em suspensão (TSS). Já a temperatura da água foi verificada em campo com a utilização do termômetro digital.

Para a verificação do uso e cobertura da terra na área da bacia hidrográfica do reservatório estudado, foi realizada a classificação através do software ENVI Classic 5.3 (ESRI,2014), foram utilizadas imagens do sensor Operacional Terra Imager (OLI) do satélite LANDSAT - 8 do dia 18 de Janeiro de 2016 disponíveis gratuitamente através do catálogo de imagens do site do Instituto Nacional de Pesquisas Espaciais (INPE).

A classificação relativa ao uso do solo, através da imagem de satélite, foi realizada pelo método supervisionado a partir do classificador Bhattacharya, que segundo Moreira (2005) utiliza técnica de classificação por regiões, que são separadas durante o processo de segmentação. Através desta classificação foram então estabelecidas 5 classes para o uso do solo sobre a área da bacia hidrográfica do reservatório, sendo elas: Floresta, agricultura, solo exposto, área urbana e água, onde a área urbana foi delimitada através da interpretação visual. 
As amostras da imagem de satélite foram obtidas através do método de amostragem estratificada aleatória partindo de uma análise visual para identificar a que classe elas representavam, levando-se em consideração aspectos como a tonalidade, cor, textura, forma, entre outros.

Para a aquisição dos valores de Condutividade Elétrica em cada uma das amostras, foi utilizado o condutivímetro ORION 815, calibrado com solução $1413 \mu \mathrm{S} / \mathrm{cm}$ (Micrômetros por centímetro) disponível no Laboratório de Geotecnologias (LABGEOTEC) da Universidade Federal de Santa Maria (UFSM).

Para a obtenção dos valores de Totais de Sólidos Suspensos (TSS) foi utilizado o método de filtragem da água conforme apresentado em APHA (2005). O processo se consiste na filtragem da água com a utilização de uma bomba de vácuo. O filtro utilizado para a filtragem é composto por celulose (indicado para análises microbiológicas, Marca Milipore-HAWG04700) constituído por membranas HA em Ester de celulose com porosidade certificada de $0,45 \mu \mathrm{S}$ e diâmetro de $47 \mathrm{~mm}$ (Milipore, 2008). O volume de água que foi utilizado no processo de filtragem correspondia a $150 \mathrm{ml}$. O procedimento teve início com a secagem dos filtros durante 24 horas em uma estufa a $50^{\circ} \mathrm{C}$ de temperatura para anular a presença de umidade, resultando assim no Pi (Peso Inicial). Após isso, os filtros são pesados em balança analítica da marca Bel $®$ Engineering (acurácia de $0,0001 \mathrm{~g}$ ) e logo após encaminhados para a filtragem das amostras de água. Por fim os filtros foram novamente conduzidos a estufa sobre as mesmas condições de tempo e temperatura, e pesados posteriormente, para que se tivesse a obtenção do Pf (Peso Final).

O TSS (mg/L) é determinado através da seguinte equação:

$$
\mathrm{TSS}=[(\mathrm{Pf}-\mathrm{Pi}) / \mathrm{V}] \times 1000
$$

Onde:

TSS - Total de Sólidos em Suspensão

Pf - Peso Final (g)

Pi - Peso Inicial (g)

$\mathrm{V}$ - Volume (L)

\subsection{Características gerais das áreas de estudo}

A Bacia Hidrográfica do Reservatório Ernestina se localiza no centro-norte do Rio Grande do Sul (Figura 1) e faz limite com 5 municípios: Ernestina, Ibirapuitã, Marau, Nicolau Vergueiro e Tio Hugo.

A Usina Hidrelétrica (UHE) Ernestina é o primeiro reservatório no sentido do fluxo da água no rio Jacuí, e se localiza a $190 \mathrm{Km}$ por via fluvial do reservatório da UHE Passo Real. No entorno do Reservatório é 
possível observar alguns aglomerados residenciais a fins de lazer, juntamente com matas nativas, silviculturas e plantações. O local tem predomínio de latossolos que se caracterizam como bem estruturados, profundos, drenados e porosos e que com o auxílio do relevo suave ondulado, indica grande capacidade de produção agrícola (CEEE 2010).

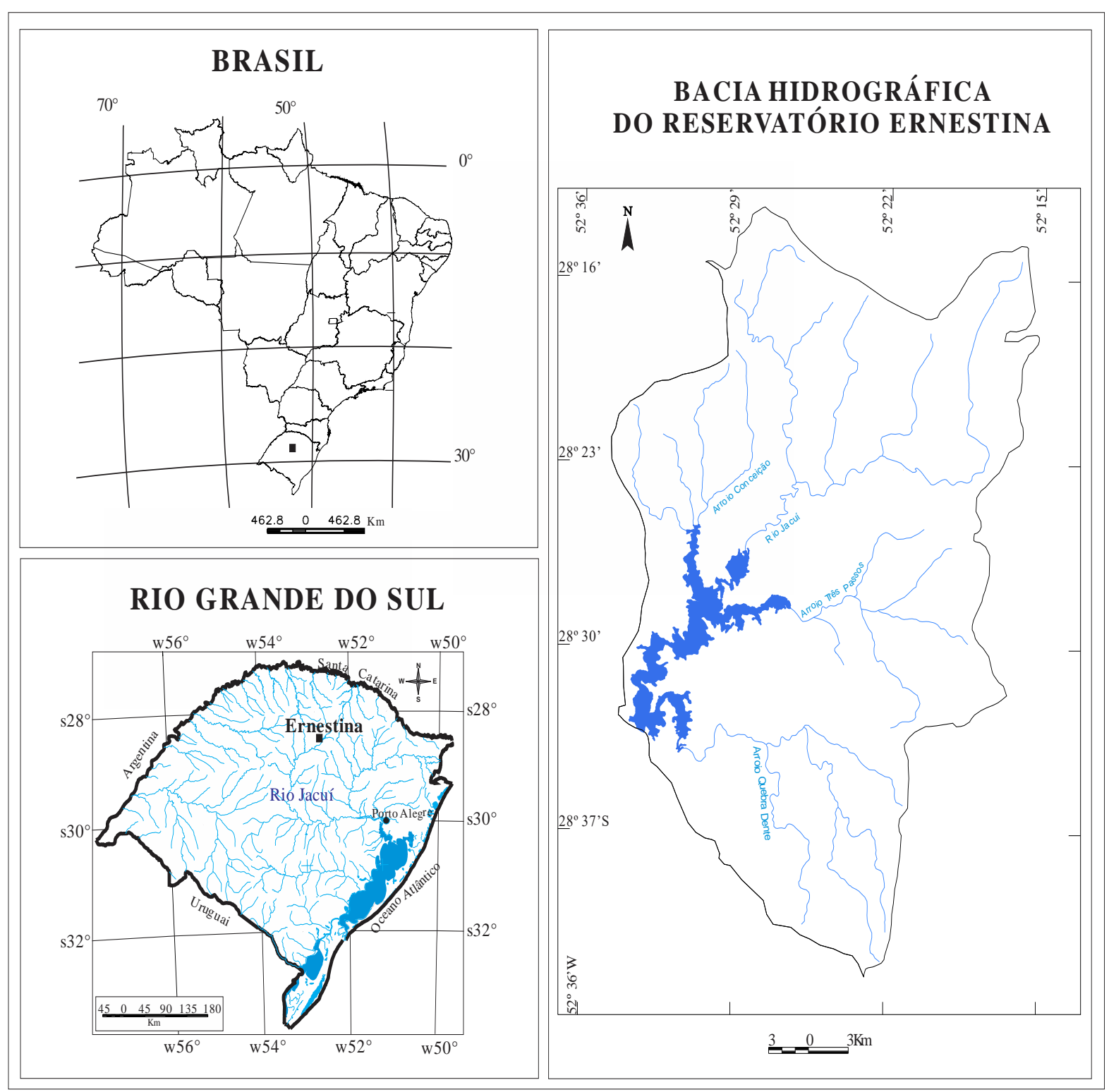

Figura 1: Mapa de Localização da Bacia Hidrográfica do Reservatório Ernestina.

\section{Resultados e discussão}

\subsection{Precipitação Pluviométrica}




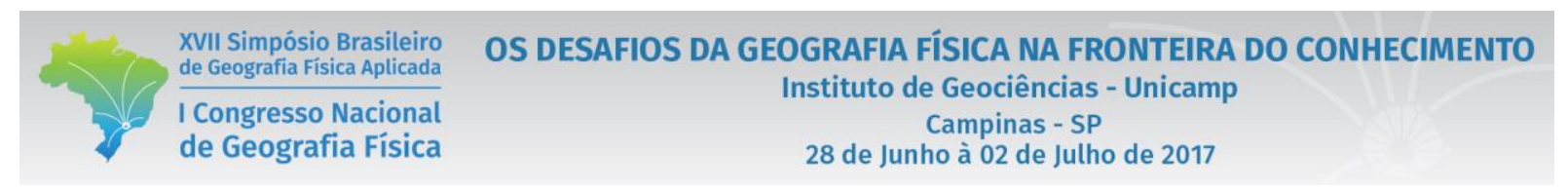

Através do gráfico da figura 2, é possível observar o índice pluviométrico referente aos 30 dias anteriores ao trabalho de campo, assim temos uma importante ferramenta no momento de analisar sua interferência sobre o escoamento superficial e transporte de detritos influenciando assim nas características limnológicas.

Nota-se que o valor mais expressivo relativo ao índice de precipitação pluviométrica foi registrado no dia 16 de janeiro, muito próximo da data de realização do trabalho de campo, isso faz com que a precipitação possa acarretar em alguma mudança com relação ao TSS e a CE das amostras ao longo da barragem.

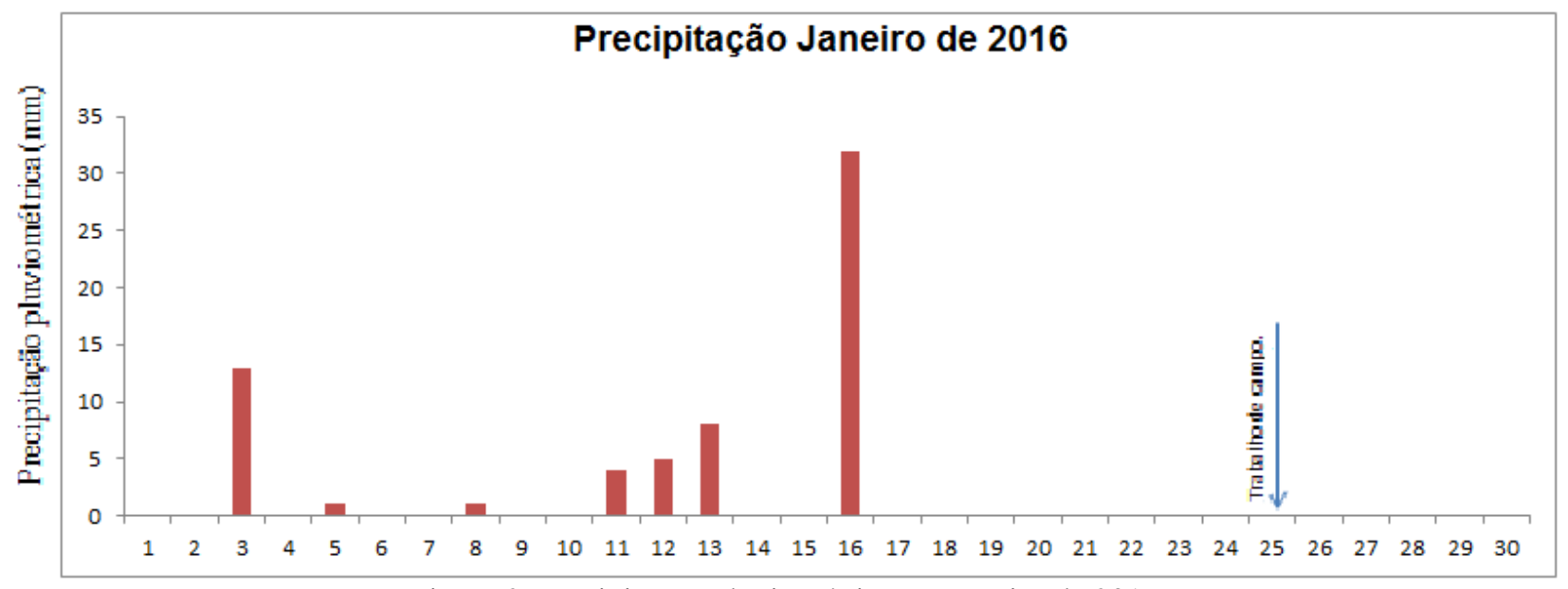

Figura 2: Precipitação Pluviométrica em Janeiro de 2016.

\subsection{Variáveis Limnológicas}

Através dos distintos índices relacionados a precipitação obtidos no período que antecede o trabalho de campo, as variáveis limnológicas temperatura, condutividade elétrica e totais de sólidos suspensos foram analisadas para então caracterizar a qualidade da água do reservatório da Usina Hidrelétrica Ernestina.

\subsubsection{Temperatura}

Conforme o gráfico da figura 3 é possível notar que as temperaturas da água nos pontos amostrais seguiram um padrão aproximado, com $1^{\circ} \mathrm{C}$ de diferença entre o ponto com maior temperatura e o de menor temperatura. Essas altas temperaturas se explicam devido a data em que foi realizado o trabalho de campo, 25 de janeiro de 2016, verão no Rio Grande do Sul, que apresenta grandes valores de temperatura do ar, e consequentemente das amostras d'água. 


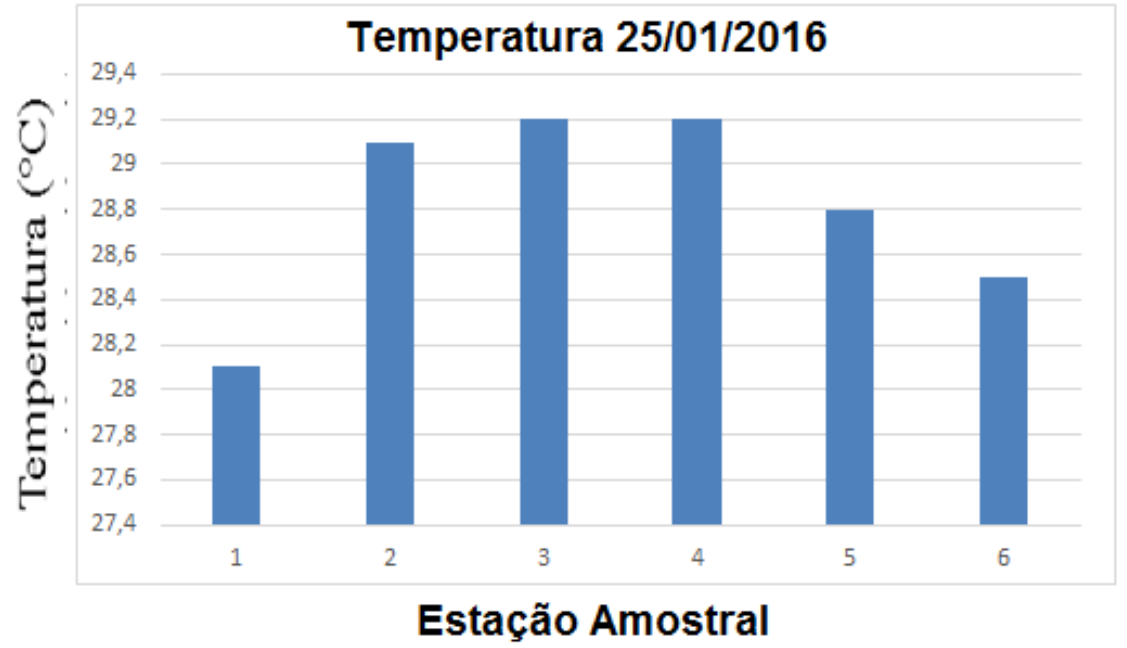

Figura 3: Temperatura nas estações amostrais analisadas.

\subsubsection{Total de Sólidos em Suspensão}

Segundo Tchobanoglous e Schroeder (1987) o TSS se apresenta como todo o material particulado em suspensão na água que não pode passar por um filtro de $0,45 \mu \mathrm{m}$. Ele está diretamente relacionado com a ocupação do entorno da, pois a carga de sedimentos é facilitada pelo tipo de ocupação.

A figura 4 apresenta os valores do TSS, sendo que o maior valor é referente ao ponto amostral $\mathrm{n}^{\circ} 4$, devido à localização das estações amostrais próximas a foz dos tributários, e pela ocupação do uso do solo nas margens do reservatório.

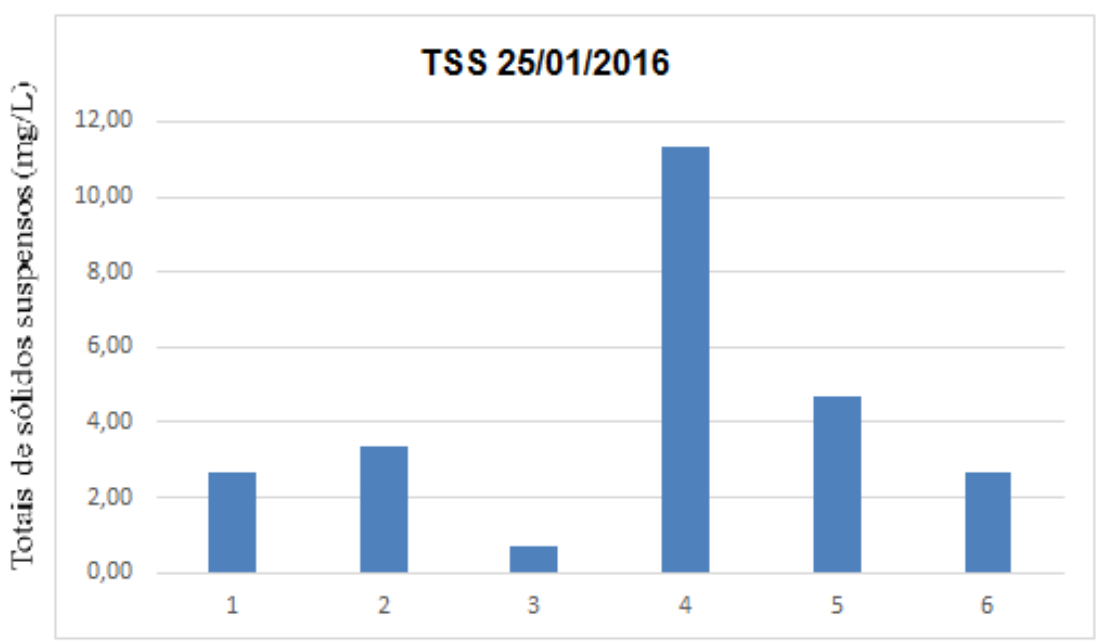

ESTAÇÄO AMOSTRAL

Figura 4: TSS das amostras analisadas. 
Os outros pontos amostrais mantiveram-se com valores estáveis entre 2 e $5(\mathrm{mg} / \mathrm{L})$. Essa diferença entre o ponto com maior valor e os demais pode ter relação com o uso e cobertura da terra nas margens da barragem, próximo aos pontos de coleta, que acabam afetando de modo mais significativo na estação amostral 4. Outro fator importante para o valor mais alto nesta estação é a influência do tributário em área de solo exposto, fazendo com que os valores de TSS deste ponto sejam significativamente maiores que os demais.

\subsubsection{Condutividade Elétrica}

Através das análises no laboratório, chegou-se aos resultados de condutividade elétrica das 6 estações amostrais. O gráfico da figura 5 apresenta os resultados, através dele é possível notar valores relativamente baixos das amostras analisadas.

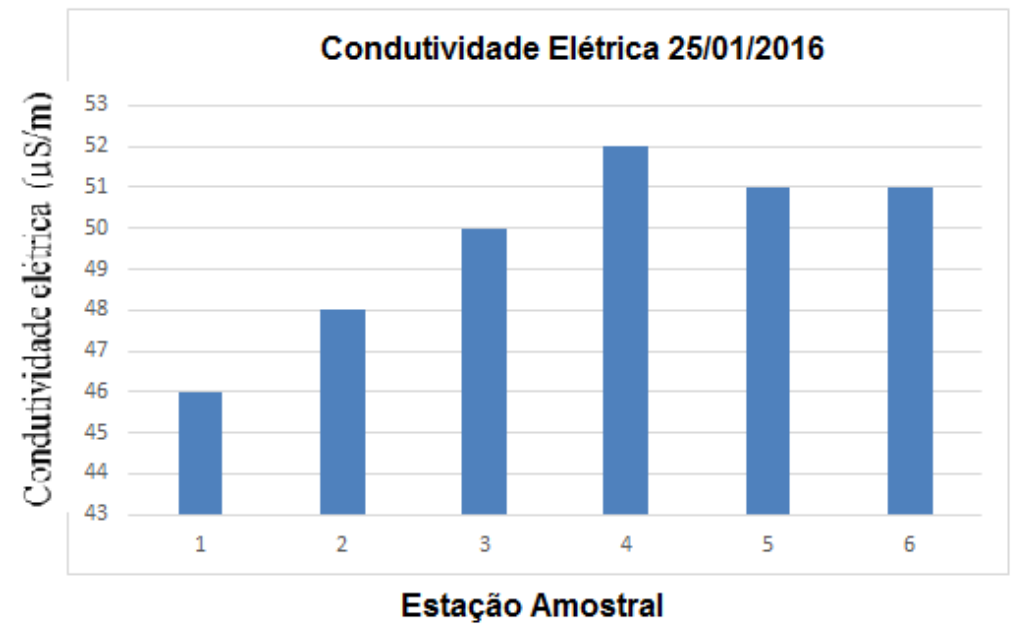

Figura 5: Condutividade Elétrica das amostras analisadas.

Isso ocorre provavelmente devido as chuvas que ocorreram nos dias que antecederam o trabalho de campo, pois assim como afirma Esteves (1998) quanto maior o índice pluviométrico, menor será o valor de condutividade elétrica.

\subsection{Uso e cobertura da terra}




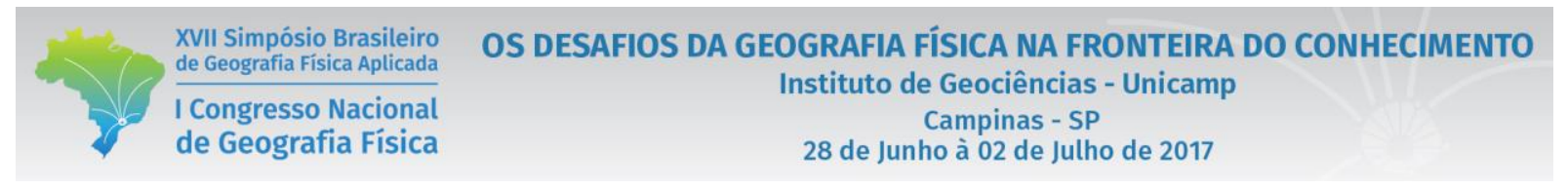

Com a utilização da imagem do satélite LANDSAT 8 do dia 18 de janeiro de 2016 foi realizada a classificação de uso e cobertura da terra da Bacia Hidrográfica do Reservatório Ernestina, apresentada na figura 6.

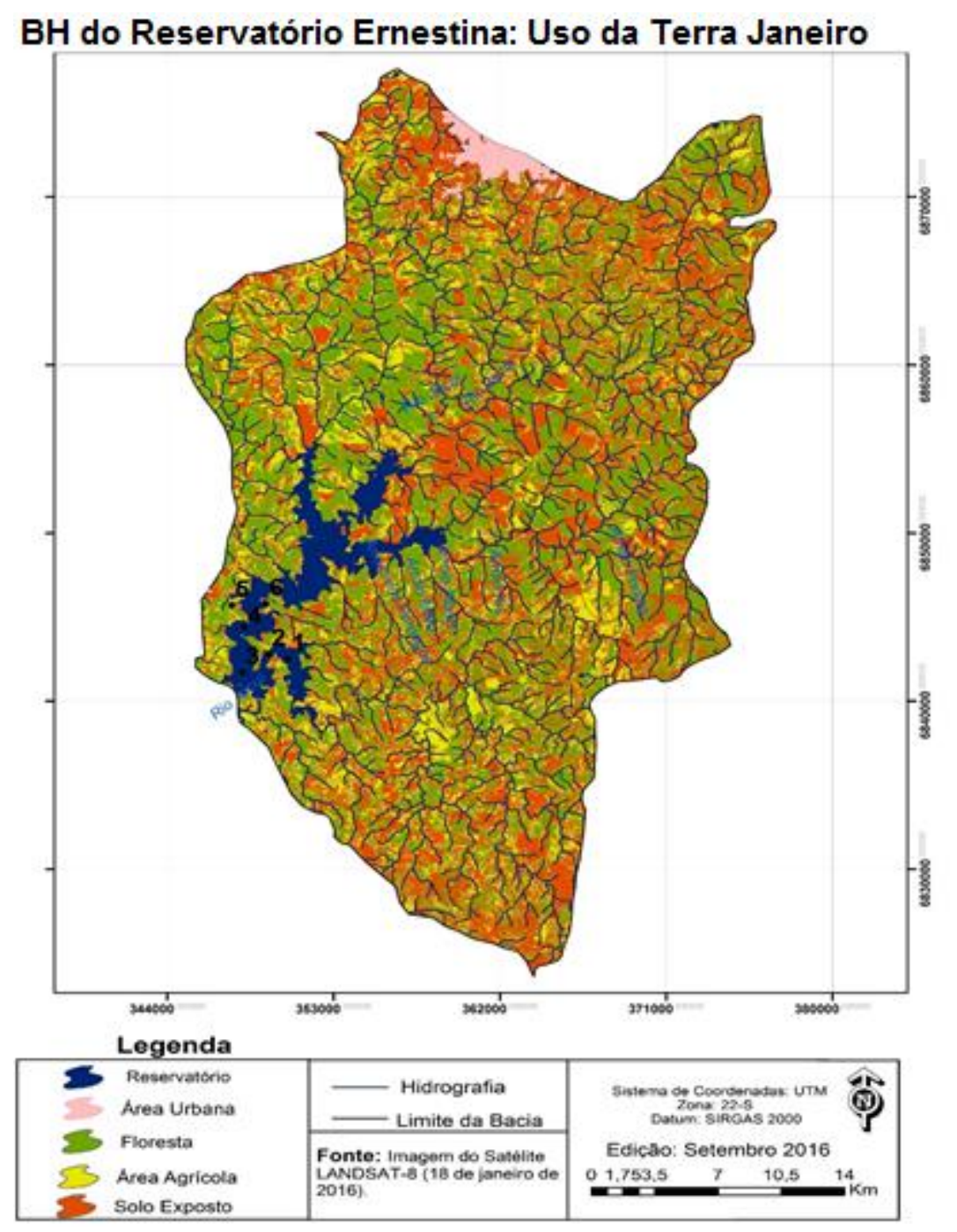

Figura 6: Uso e Cobertura da Terra da Bacia Hidrográfica do Reservatório Ernestina em janeiro de 2016.

Através dela foi possível perceber uma grande quantidade da classe temática solo exposto, isso se deve a preparação da terra para os cultivos agrícolas para a colheita nos próximos meses, neste caso é o preparo da terra para a plantação de soja. 
Como salientado anteriormente no entorno do reservatório é possível notar algumas moradias residenciais voltadas ao lazer, através da imagem de satélite também se nota a grande porção relativa a classe temática "floresta" que é relativo as matas nativas e também pelas silviculturas que se encontram dentro da microbacia.

Esse solo exposto apresenta grande influência com relação ao Total de Sólidos em Suspensão principalmente na estação amostral 4 que está localizada próxima a margem que apresenta solo exposto e área agrícola.

\section{Considerações finais}

Este trabalho teve como objetivo identificar a influência da precipitação pluviométrica e do uso e cobertura da terra nas variáveis limnológicas do reservatório da usina hidrelétrica Ernestina no mês de janeiro de 2016. Através da análise dos dados adquiridos é possível concluir que o uso e cobertura da terra, juntamente com a precipitação pluviométrica apresentam relações diretas nas variáveis limnológicas, principalmente na Condutividade Elétrica e no Total de Sólidos em Suspensão.

Analisando o trabalho de (KAISER et al., 2015) que utilizou a mesma área de estudo, é possível notar algumas diferenças referentes ao uso e cobertura da terra, principalmente com a classe temática "floresta" que em 2016 se apresenta um pouco maior, uma das explicações para isso é algum possível erro no classificador que possa ter adicionado zonas de pastagem nesta classe temática. Ainda com relação a este trabalho que teve seu campo realizado no ano de 2012, podemos correlacionar as variáveis transparência e TSS, que tiveram resultados aproximados quando comparados com ocasiões de pouca precipitação nos dias anteriores ao campo. Desta forma, podemos notar que essas variáveis são mais influenciadas pelo tipo de uso e cobertura da terra.

Com a utilização de técnicas de geoprocessamento e sensoriamento remoto para a manipulação das imagens de satélite foi possível realizar a classificação do uso e cobertura da terra da bacia hidrográfica do reservatório para o mês analisado. Este dado em conjunto com os dados de precipitação pluviométrica e os resultados das amostras em laboratório, acabam nos mostrando que o presente trabalho atingiu os objetivos propostos.

De modo geral, é possível verificar a espacialização das características da bacia hidrográfica do reservatório, vinculadas a ação do clima e da ação antrópica nas margens do mesmo. 


\section{Agradecimentos}

Os autores agradecem ao Programa Institucional de Bolsas de Iniciação Científica (PIBIC/CNPq) pelo apoio financeiro e ao Instituto Nacional de Pesquisas Espaciais (INPE) pelo suporte. Também agradecemos ao colega de laboratório Joceli Augusto Gross pelo auxilio na coleta das amostras através do trabalho de campo.

\section{Bibliografia}

APHA - American Public Health Association. Standard Methods for the Examination of Water and Wasterwater. 21 ed. Sprimgfield: Byrd Prepress, 2005.

CARVALHO, A.R.; SCHLITTLER, F.H.M.; TORNISIELO, V.L.; Relações da atividade agropecuária com parâmetros físicos químicos da água. Química Nova, 23(5): p. 618-622, 2000.

CEEE-GT (2010): (Companhia Estadual de Geração de Energia Elétrica - Geração e Transmissão). Plano de uso e ocupação do solo no entorno do Reservatório da UHE Ernestina. Porto Alegre, PROFFIL. [Consulta: 30-01-2017]. Disponível em http://www.ceee.com.br/pportal/ceee/archives/solo/jacui/reservatorio_ernestina.pdf.

COAJU - Comitê de Gerenciamento da Bacia Hidrográfica do Alto Jacuí. Plano de Gerenciamento da Bacia Hidrográfica do Alto Jacuí: consolidação das informações existentes sobre os recursos hídricos da bacia. Relatório Temático - RT 2, 2009, Passo Fundo, 2009.

ESTEVES, F. A. Fundamentos de Limnologia. 2 ed. Rio de Janeiro: Interciência, 1998.

HADLICH, G. M. e SHEIBE, L. F. Dinâmica físico-química de água superficiais em região de intensa criação de suínos: exemplo da bacia hidrográfica do rio Coruja-Bonito, município de Braço do Norte, SC. Geochimica Brasiliensis, v.21, n. 3, p. 245-260, 2007.

KAISER, Eduardo André; DOS SANTOS, Felipes Correa; PEREIRA FILHO, Waterloo. Influência da precipitação pluviométrica e uso da terra em variáveis limnológicas do reservatório da usina Hidrelétrica Ernestina, RS. GeoFocus. Revista Internacional de Ciencia y Tecnología de la Información Geográfica, n. 16, p. 3-22, 2015.

MOREIRA, M. A. Fundamentos de sensoriamento remoto e metodologias de aplicação. 3 ed. Viçosa: Ed. UFV, 2005.

TCHOBANOGLOUS G. \& SCHROEDER E.D. 1987. Water Quality Management. Addison-Wesley Publishing Company .Ed. Volume I Longman. 768 p.

TODESCHINI, M. L. Dinâmica espacial e temporal das características físicas e químicas do rio Cubatão e distribuição espacial da bacia hidrográfica - litoral do Paraná. Dissertação (Mestrado em Geologia Ambiental) Universidade Federal do Paraná, Curitiba, 2004.

WALKER, I. Amazonian stream and small rivers. In: TUNDISI, J. G.; BICUDO, C. E. M.; MATSUMURA TUNDISI, T (Eds.) Limnology in Brazil. Rio de Janeiro: Brazilian Academy of Science, p. 167-193, 1995. 